\title{
Trait Anger and Anger Expression Styles in Muay Thai Athletes
}

\author{
Ferhat Ustun ${ }^{1} \&$ Erdal Tasgin ${ }^{1}$ \\ ${ }^{1}$ Selcuk University, Faculty of Sports Sciences, Konya, Turkey \\ Correspondence: Erdal Tasgin, Selcuk University, Faculty of Sports Sciences, Konya, Turkey. E-mail: \\ erdaltasgin@selcuk.edu.tr
}

Received: December 29, 2019

Accepted: January 30, 2020 Online Published: January 31, 2020

doi:10.5539/jel.v9n1p258

URL: https://doi.org/10.5539/jel.v9n1p258

\begin{abstract}
In this research, Muay Thai athletes who are university students have been examined by evaluating trait anger and anger expressions in terms of some variables. One hundred and ninety-five Muay Thai Athletes from Turkey Muay Thai Championship between universities volunteered for the study. "The Trait Anger and Anger Expression Scales" by Spielberger was used to determine the trait anger and anger expression styles of participants. Kruskal Wallis $\mathrm{H}$ and Mann Whitney $\mathrm{U}$ tests were applied for statistical analysis and comparison of variables.

According to the general results of the study; for Anger/In subscale, male athletes had higher points than female athletes. The mothers of high school graduates have higher Anger-In scores than whose mothers had university graduate, and whose father had high school graduate, than in athletes, whose father had primary school graduate. It was found that athletes, whose mothers had secondary school graduate, had higher anger/out subscale points than athletes, whose mothers had primary school graduate and university graduate. Anger/in subscale points of athletes, who had 9 years and more of sport experience, were higher than athletes, who had a lower of sport experience. Those with 3-4 years of sport experience had higher anger/out subscale points than those with 1-2 years and 9 years and more of sport experience. Those with 9 years and more had higher anger-control subscale points than those with a lower of sport experience. There was no significant difference in trait anger and anger/in subscales points between athletes joined international tournaments and who did not. There was a significant different in anger/out and anger/control subscales points between athletes joined international tournaments and who did not.

As a result, Muay Thai athletes, who are university students, have differences in the forms of trait anger and anger expressions in the dimensions of family (parents' education level), sporting time and participation in international competitions, the positive incentives of the family to sports, the experiences of the individual in the field of sports and the sense of self-realization have been evaluated that they have a motivational and positive effect on managing, controlling, or suppressing anger.
\end{abstract}

Keywords: anger, anger expression styles, Muay Thai, university, motive

\section{Introduction}

Sports enables individuals to be healthy, be developed in social and emotional aspects and let them increase their knowledge and skills (Sunay \& Saracoglu, 2003). Sports can be done individually or within a group. Sports, as well as the physical development of people, makes them psychologically strong. During sports activities, people can convey their emotions nonverbally and control the reflection of their different emotions (Herguner, 1991; Ozturk Akcalar, 2007; Tanriverdi, 2012). Sportive activities can also help to effectively control and suppress certain feelings such as aggression and anger. In this context, it has positive effects in terms of harmony of individuals (Kuru, 2003). It is suggested that anxiety and stress decrease with regular sports activities (Hassmen et al., 2000).

It is stated that with the effective regulation of human emotions athletic performances of athletes were improved positively and the available power was maximized and individuals were enabled to control their emotions with the introduction of the communication and interaction factors of the team members (Perkins et al., 2001; Moll et al., 2010; Beedie \& Lane, 2012). Emotions are effective in shaping people's goals. For example, emotions are functional in situations where emotions such as anger or fear motivate people, and in situations where they cause problems (such as an athlete making mistake by anger) they are not functional (Nesse \& Ellsworth, 2009; Gross 
\& Barrett, 2011).

According to the researches performed, unpleasant feelings such as anger and anxiety can also be effective in increasing performance. People do not hesitate to be affected by their negative feelings when they feel they will benefit them (Beedie et al., 2000; Tamir, 2009; Hanin, 2010). It was determined that "anger" can affect sportive performance positively or negatively. It has been determined that anger is decreased, self-control ability is increased, and problem-solving skills are strengthened in persons doing sports (especially in adolescents) (Opoz, 2017). It is thought that by using anger emotion efficiently, the ability to get focused and think healthily during sports activities will be improved and decision-making and implementation will accelerate (Jones, 2003). It is suggested that the anger is more effective in situations where more aggressive playing is needed compared to normal time (Lazarus, 2000).

"Self-esteem", which is an important part of the concept of personality and anger, which is a common feeling in individuals' relationships, affects all aspects of human life and directs their actions. Copersmith (1967) suggested that self-esteem, as a positive and important element of self, is an individual's level to see him/herself as skilled, valuable, successful and important person. It can be stated that self-esteem enhances person's recognition of themselves, recognition of his/her skills and power, and consequently increases feelings of love, respect and trust for him/herself and his/her environment (Cuhadaroglu, 1986). Anger is defined in various ways. Kennedy (1992) summarized the emotion of anger; by describing it as a phenomenon that arises as a result of an individual's warning to others due to a danger directed to him/herself, Kisac (1997) describes it as one of the basic emotions experienced by an individual when his/her plans, desires and needs are hindered or when he/she perceives an injustice act or a threat to his/herself (Bahadir \& Certel, 2012).

The emotion of anger is natural for the continuity of people's lives. However, most people face problems due to anger. In addition to this, due to the effects of the cultural structure, people are afraid or unwilling to show anger. However, when the emotion of anger is suppressed, the current energy is turned inward and thus the self-harms $\mathrm{him} /$ herself and thehis/her environment. The concept of coping with the anger does not require suppression and hiding, but rather recognizing it. It is healthier to constructively express and direct the anger, which is a natural feeling for the individual and the athletes who are the subject of the research. It can be stated that the roots of most of the individual and social problems were based on the anger that was not properly expressed (Bahadir \& Certel, 2012).

The anger is experienced in people in different ways. These; introversion of the anger, outpouring of the anger and the anger control. Outpouring of the anger; anger is reflected to the outside by verbal or behavioral means. Introversion of the anger; it is the individual's hiding and keeping the anger in or developing an alternative adaptation mechanism against its agents. The anger control; is a situation and control experience, which demonstrates that to the what extent an individual controls his/her anger or calms down in his/her relationship with other people (Bostanc1 et al., 2006; Ozer, 1994; Starner \& Peter, 2004; Tanbag \& Oz, 2005).

In this study, constant anger and anger expression styles of university students who were also interested in Muay Thai sport were examined according to some variables. 195 athletes those who participated in the Turkey Inter-Universities Muay Thai Championships have participated in the study voluntarily. In order to determine the constant anger and anger expression styles, "Constant Anger and Anger Expression Style Scale" which was developed by Spilberger and adapted to Turkish by Özer was applied to the participant athletes. Kruskal Wallis $\mathrm{H}$ and Whit Mann Whitney $\mathrm{U}$ analysis methods were used for comparison of variables and statistical analyzes. Constant anger levels and anger expression styles of Muay Thai athletes were evaluated by considering dimensions such as education levels of their parents, duration of their sports life and participation in international competitions.

\section{Material and Method}

In this study, where the Constant Anger and Anger Styles of the participants were investigated, screening model was used. The population of the study is consisting of athletes participating in the Turkey Inter-University Championship. Of the 220 athletes who participated in the Muay Thai championship held in Antalya/Kemer-Kiriş-Daima Hotel in 2017, 195 athletes who voluntarily agreed to participate in the study formed the population of this study.

\subsection{Data Collection Method}

In this study, a questionnaire was used as the main data collection method. In order to collect the data of the study, two separate questionnaires were provided to the participants. In the first questionnaire form, descriptive information about the participants (gender, education level of parents, sports experience and participation in 
international competitions), and in the second questionnaire form Constant Anger and Anger Styles Scale questions took place. The questionnaire forms were given to the participants by the researcher in a one-to-one interview and collected after the answers to the survey questions were completed.

\subsection{Constant Anger and Anger Styles Scale}

Constant Anger and Anger Styles Scale, which is a self-assessment scale, measures anger emotion and expression. The scale was developed by Smith et al. (1983) and adapted to Turkish by Dogan (1994). It is consisting of four dimensions as four-point Likert type (1: Never defines, 2: Some defines, 3: Highly defines, 4: Totally defines) in a four-point Likert Type and a scale formed by total of 34 items such as Constant Anger (SL Anger 10 items), introvert anger (introvert anger, 8 items), outpouring anger (outpouring anger: 8 items), and controlled anger (anger control, 8 items). Increased scores in the SL-Anger dimension indicate high anger, high scores in the introvert anger dimension indicate suppressed anger, high scores in the outpouring Anger dimension indicate that anger can be easily expressed, and high scores in the Anger-Control dimension indicate that anger can be controlled.

Scale items according to scale dimensions are as follows: For SL-Anger 1, 2, 3, 4, 5, 6, 7, 8, 9, 10; For introvert anger 13, 15, 16, 20, 23, 26, 27, 31; for outpouring anger 12, 17, 19, 22, 24, 29, 32, 33; and Anger control 11, 14, $18,21,25,28,30,34$. The scores obtained in each dimension were summed and the scores of the participants were calculated separately for 4 dimensions.

In the reliability study conducted by Ozer (1994), the internal consistency coefficients of the scale were reported as; for SL-Anger dimension 79, for introvert anger dimension 62, for outpouring anger dimension 78 and for Anger-Control. Dimension 84.

\subsection{Data Analysis}

The presentation of the data obtained in the research is given as average value and standard deviation. The normality test was performed by using Shapiro-Wilk test. Since the scale scores of the participants did not show normal distribution according to the independent variables that were evaluated, non-parametric analysis methods were preferred in the comparison of the groups. Mann-Whitney $U$ test was used for comparison of dual independent groups and Kruskal-Wallis $\mathrm{H}$ test was used for comparison of multiple independent groups. Statistical significance level was accepted as 0.05 . SPSS 22.0 statistical package program was used in all statistical calculations.

\section{Result}

The sub-scale scores of the Constant Anger and Anger Style Scale according to gender variable are presented in Table 1. While SL-Anger $(U=2329.000 ; p=0.780)$ and Outpouring Anger $(U=2134.500 ; p=0.354)$ did not differ according to the gender variable, introvert anger $(\mathrm{U}=1351.500 ; \mathrm{p}=0.000)$ and Anger-Control $(\mathrm{U}=$ $1054.000 ; p=0.000)$ scores were found to be statistically significant. The Introvert Anger and Anger-Control scores of male participants were higher than female participants $(\mathrm{p}<0.05)$.

Table 1. The distributions of the scores of continuous anger and anger style scale according to gender variable

\begin{tabular}{|c|c|c|c|c|}
\hline Variables & Gender & $\mathrm{N}$ & Mean & Std. deviation \\
\hline \multirow[t]{2}{*}{ SL-Anger } & women & 29 & 24.83 & 6.23 \\
\hline & men & 166 & 24.92 & 6.59 \\
\hline \multirow[t]{2}{*}{ Anger-inwardly } & women & 29 & 17.00 & 3.78 \\
\hline & men & 166 & $20.76^{*}$ & 5.20 \\
\hline \multirow{2}{*}{ Anger-outside } & women & 29 & 18.86 & 4.82 \\
\hline & men & 166 & 20.06 & 5.80 \\
\hline \multirow[t]{2}{*}{ Anger-control } & women & 29 & 19.00 & 4.95 \\
\hline & men & 166 & $24.45^{*}$ & 4.99 \\
\hline
\end{tabular}

Note. Signs $(*)$ in the same column are statistically significant $(\mathrm{p}<0.05)$.

When the scores of Constant Anger and Anger Style Scale were compared according to mother's educational status (Table 2); SL-Anger (Chi-Square $=7.745 ; \mathrm{p}=0.052)$ and Anger-Control $($ Chi-Square $=2.611 ; \mathrm{p}=0.456)$ scores were not found to be significantly different $(\mathrm{p}>0.05)$, however introvert anger $($ Chi-Square $=10.512) ; \mathrm{p}$ $=0.015)$ and outpouring anger (Chi-square $=11.147 ; \mathrm{p}=0.011)$ scores were found to be significantly different according to the educational status of the mother $(\mathrm{p}<0.05)$. According to this, it was established that the introvert anger scores of whose mothers were junior high school graduates were higher than whose mothers were 
elementary school graduates $(U=1471.500 ; p=0.047)$ and whose mothers have undergraduate degrees $(U=$ $78.000 ; p=0.002)$; however, introvert anger scores of whose mothers were high school graduates $(U=130.500$; $\mathrm{p}=0.013)$ were higher than whose mothers have undergraduate degrees $(\mathrm{p}<0.05)$. For outpouring anger scores, it was determined that outpouring anger scores of whose mothers were junior high school graduates were higher than whose mothers were elementary school graduates $(U=1276.500 ; p=0.003)$ and whose mothers have undergraduate degrees $(\mathrm{U}=121.000 ; \mathrm{p}=0.024)(\mathrm{p}<0.05)$.

Table 2. Distribution of the anger and anger style scale scores according to the mother's educational level

\begin{tabular}{lllll}
\hline & & N & Mean & Std. deviation \\
\hline SL-Anger & junior school & 73 & 23.89 & 6.72 \\
& junior high school & 53 & 24.44 & 5.30 \\
& high school & 60 & 26.73 & 6.82 \\
& degree & 9 & 24.78 & 7.34 \\
Anger-inwardly & Total & 195 & 24.96 & 6.50 \\
& junior school & 73 & 19.48 & 5.63 \\
& junior high school & 53 & $21.06^{*}$ & 3.91 \\
& high school & 60 & $20.82^{* *}$ & 5.51 \\
Anger-outside & degree & 9 & 16.33 & 3.24 \\
& Total & 195 & 20.17 & 5.18 \\
& junior school & 73 & 18.62 & 5.30 \\
& junior high school & 53 & $21.73^{* * *}$ & 6.51 \\
& high school & 60 & 20.22 & 5.02 \\
& degree & 9 & 18.33 & 4.85 \\
& Total & 195 & 19.92 & 5.65 \\
& junior school & 73 & 23.74 & 5.45 \\
& junior high school & 53 & 24.04 & 4.83 \\
& high school & 60 & 23.48 & 5.59 \\
& degree & 9 & 21.33 & 5.98 \\
& Total & 195 & 23.63 & 5.35 \\
\hline
\end{tabular}

Note. $*$ The mother is significantly higher than the primary and undergraduate graduates $(\mathrm{p}<0.05)$.

** His mother is significantly higher than those with a bachelor's degree $(\mathrm{p}<0.05)$.

$* * *$ The mother is significantly higher than the primary and undergraduate graduates $(\mathrm{p}<0.05)$.

Table 3. Distribution of the anger and anger style scale scores according to father education level

\begin{tabular}{lllll}
\hline & & $\mathrm{N}$ & Mean & Std. deviation \\
\hline SL-Anger & junior school & 39 & 22.97 & 7.03 \\
& junior high school & 12 & 23.58 & 5.99 \\
& high school & 118 & 25.60 & 6.31 \\
& degree & 26 & 25.27 & 6.61 \\
Anger-inwardly & Total & 195 & 24.91 & 6.52 \\
& junior school & 39 & 18.54 & 5.06 \\
& junior high school & 12 & 18.00 & 4.43 \\
& high school & 118 & $20.80^{*}$ & 5.10 \\
Anger-outside & degree & 26 & 20.96 & 5.52 \\
& Total & 195 & 20.20 & 5.19 \\
& junior school & 39 & 19.38 & 7.94 \\
& junior high school & 12 & 18.50 & 4.62 \\
& high school & 118 & 20.18 & 4.83 \\
Anger-control & degree & 26 & 19.92 & 5.73 \\
& Total & 195 & 19.88 & 5.67 \\
& junior school & 39 & 21.97 & 4.71 \\
& junior high school & 12 & 22.17 & 4.69 \\
& high school & 118 & 24.24 & 5.46 \\
& degree & 26 & 24.12 & 5.58 \\
& Total & 195 & 23.64 & 5.34 \\
\hline
\end{tabular}

Note. ${ }^{*}$ The father is significantly higher than the primary school graduates $(\mathrm{p}<0.05)$. 
The distribution of the scores of the Constant Anger and Anger Style Scale according to the father's education level is presented in Table 3. According to results of multiple comparison; it was determined that SL-Anger $($ Chi-Square $=6.137 ; \mathrm{p}=0.105)$, outpouring anger $($ Chi-Square $=4.874 ; \mathrm{p}=0.181)$ and Anger-Control scores (Chi-Square $=7.472 ; \mathrm{p}=0.058$ ) values were not significantly different according to education level. Of fathers $(\mathrm{p}>0.05)$. However, the introvert anger scores were found to be statistically significant according to educational level of fathers (Chi-Square $=8.883 ; \mathrm{p}=0.031$ ). As a result of dual comparisons; it was found that those whose fathers were high school graduates had significantly higher Introvert Anger scores than those whose fathers were elementary school graduates $(U=1638.000 ; p=0.008)$.

Table 4. The distributions of the anger and anger style scale scores according to the sport experience variable

\begin{tabular}{lllll}
\hline & & N & Mean & Std. deviation \\
\hline SL-Anger & 1-2 years & 26 & 24.96 & 6.02 \\
& 3-4 years & 20 & 22.50 & 5.34 \\
5-6 years & 19 & 21.74 & 5.85 \\
7-8 years & 16 & 25.13 & 6.87 \\
9 and more years & 114 & 25.82 & 6.70 \\
Total & 195 & 24.91 & 6.52 \\
& 1-2 years & 26 & $18.00^{*}$ & 4.70 \\
3-4 years & 20 & $16.95^{*}$ & 4.71 \\
& 5-6 years & 19 & $17.74^{*}$ & 4.07 \\
& 7-8 years & 16 & 19.19 & 4.82 \\
& 9 and more years & 114 & 21.83 & 5.00 \\
& Total & 195 & 20.20 & 5.19 \\
& 1-2 years & 26 & $20.38^{* *}$ & 4.45 \\
3-4 years & 20 & 17.10 & 4.70 \\
& 5-6 years & 19 & 18.47 & 4.13 \\
7nger-outside & 7-8 years & 16 & 20.13 & 11.10 \\
& 9 and more years & 114 & $20.46^{* *}$ & 5.08 \\
& Total & 195 & 19.88 & 5.67 \\
1-2 years & 26 & $21.04^{* * *}$ & 4.39 \\
& 3-4 years & 20 & $20.30^{* * *}$ & 5.35 \\
& 5-6 years & 19 & $19.89^{* * *}$ & 4.82 \\
7-8 years & 16 & $21.25^{* * *}$ & 5.17 \\
& 9 and more years & 114 & 25.80 & 4.61 \\
Total & 195 & 23.64 & 5.34 \\
\hline
\end{tabular}

Note. $*$ Sports experience is significantly lower than those with 9 years or more $(\mathrm{p}<0.05)$.

** Sports experience is significantly higher than those with $3-4$ years $(\mathrm{p}<0.05)$

*** Sports experience is significantly lower than those with 9 years or more $(\mathrm{p}<0.05)$.

The distribution of the scores of the Constant Anger and Anger Style Scale of participants according to sports experience is presented in Table 4. According to results of performed Kruskal Wallis H test, it was determined that SL-Anger scores did not show significant difference according to sport experience (Chi-Square $=8.349 ; \mathrm{p}=$ $0.080)$. Introvert Anger (Chi-Square $=27.801 ; p=0.000)$, Outpouring Anger $($ Chi-Square $=11.641 ; p=0.020)$ and Anger-Control (Chi-Square $=48.703 ; p=0.000)$ scores were found to be significantly different according to the participants' sports experience levels.

According to the results of the dual comparison; Introvert Anger scores of participants with sport experience of 9 years or more were significantly lower than scores of those who have 1-2 years of sport experience $(\mathrm{U}=$ 824.000; $p=0.000)$, and of 3-4 years $(U=550.000 ; p=0.000)$ and of 5-6 years $(U=591.000 ; p=0.002)$.

The Outpouring Anger scores of the participants with 3-4 years of sports experience were found to be significantly lower than those with $1-2$ years of sports experience $(U=153.000 ; p=0.018)$ and those with 9 years or more $(\mathrm{U}=715.000 ; \mathrm{p}=0.009)$.

Anger control of participants with sport experience of 9 years or more were found to be significantly higher than scores of those who have $1-2$ years of sport experience $(U=618.000 ; p=0.000)$, and of $3-4$ years $(U=380.000$; $\mathrm{p}=0.000)$ and of $7-8$ years $(\mathrm{U}=465.500 ; \mathrm{p}=0.002)$. 
Table 5. Distribution of scores of continuous anger and anger style scale according to national and international competitions

\begin{tabular}{lllll}
\hline \multirow{2}{*}{ SL-Anger } & Participation in International Competition & $\mathrm{N}$ & Mean & Std. deviation \\
& Yes & 45 & 23.80 & 6.71 \\
\multirow{4}{*}{ Anger-inwardly } & No & 150 & 25.24 & 6.45 \\
& Yes & 45 & 19.22 & 5.24 \\
& No & 150 & 20.49 & 5.15 \\
\multirow{5}{*}{ Anger-outside } & Yes & 45 & $18.51^{*}$ & 5.05 \\
& No & 150 & 20.30 & 5.79 \\
& Yes & 45 & $22.20^{*}$ & 5.36 \\
& No & 150 & 24.07 & 5.28 \\
\hline
\end{tabular}

Note. $*$ Significantly lower than those giving no $(\mathrm{p}<0.05)$.

When the Constant Anger and Anger Style scores of the subjects were compared in terms of participation in international competitions (Table 5); SL-Anger $(U=2960.500 ; p=0.210)$ and Introvert Anger $(U=2796.500 ; p$ $=0.091)$ scores were not found to be significantly different $(\mathrm{p}>0.05)$. On the other hand, it was observed that the Outpouring Anger scores $(U=2608.000 ; p=0.024)$ and Anger Control $(U=2674.500 ; p=0.039)$ scores of the participants who reported that they participated in the international competitions were found to be lower than the participants who reported not participating $(\mathrm{p}<0.05)$.

\section{Discussion and Conclusion}

The aim of this study is to investigate whether there is a relationship between constant anger and anger expression styles, parental education levels, athletic experience durations and participation in international competitions in order to form the population of study of university athletes who are also interested in Muay Thai sport. In this section, the findings and the results of similar studies in the literature will be discussed.

In our study, while there was no significant difference in constant anger and anger control variables according to gender variable, a significant difference was found in introvert anger and anger control dimensions. According to this, it is observed that introvert anger and anger control scores were higher in men than women. According to the findings of the study conducted by Bahadır and Certel (2012), there was no significant difference between the introvert anger, outpouring anger control variables whether being a male or female athlete. Similarly, Balkaya (2003), Olmus (2001) and Baygol (1997) concluded that gender factor was not effective in constant anger and anger expression styles in university students and adolescents. Karatas (2008) did not find a significant difference between the variables of constant anger, introvert anger, outpouring anger and anger control in their study conducted on high school students. However, Ozmen el al. (2016), in their study conducted on 6th, 7th and 8th graders, found that there was a significant relationship between constant anger levels and outpouring anger sub-scales in terms of gender variable and no significant difference in introvert anger and anger control variables. Again, Batıgün and Utku (2006) found that male students showed more aggression, while Kısaç (1997) found that male university students had better control of their anger than female students. Tuzgol (1998), Amedahe and Owusu-Banahene (2007), in their studies suggested that males exhibit more aggressive behavior than females. Therefore, although there are different determinations according to the gender variable in the studies in the literature, when the studies with similar results are examined, it is seen that they are similar to the results in our study, that male athletes express their anger more and control their anger less. In our study, it was found that there was a statistically significant difference according to the education level of the mother in respect of the introvert anger variable. According to this, it was found that the scores of the participants whose mothers are junior high school graduates are relatively higher than those whose mothers are undergraduate and elementary school graduates, while the introvert anger scores of participants whose mothers are high school graduates are higher than those whose mothers-undergraduate graduates. According to the outpouring anger variable, the outpouring anger scores of the participants whose mothers were junior high school graduates were higher than those whose mothers had undergraduate degree and elementary school graduates. Ozmen et al. (2016) concluded that the level of education of mothers did not show a significant difference in constant anger, introvert anger and outpouring anger variables, and anger-control variable showed a significant difference. Again, in a study conducted by Gulveren (2008) on students in Ankara and Istanbul, no significant difference was found in the constant anger and anger expression styles according to the education of mother's variable. Again, in a study conducted by Gulec (2002), no significant difference was found when the mother's education level was examined in terms of constant anger and anger expression styles. In the study by Kanoglu (2008), there was no statistically significant difference in terms of constant anger and anger expression styles according to the 
education level of the mother. Altuntas (2012), in a study he conducted on adolescents, found that there was a significant difference between constant anger and outpouring anger and education level of mother. Accordingly, the level of constant anger was higher in adolescents whose mothers were university graduates than those whose mothers were elementary and junior high school graduates. According to the Outpouring Anger variable, the outpouring anger level of adolescents whose mothers were university graduates was higher than the outpouring anger levels of adolescents whose mothers were high school and junior school graduates. In the study of Kuruoglu (2009), which is similar to the findings in our study, it was concluded that there was no significant relationship between constant anger, outpouring anger and anger-control variables according to level of education of mother, and there was a significant difference in introvert anger variable. The fact that participants whose mothers' are junior high school graduates have shown relatively lower scores in all sub-anger dimensions, suggests that as education level increases, mothers rise their children to have better control on their anger, and as level of education of mother increases they become more liberal and affect their children to express their behavior styles more freely.

In our study, it was determined that the introvert anger scores of the participants whose father education level was high school were higher than those whose fathers were elementary school graduates and the introvert anger scores increased as the education level increased. Sezan (2016) in his study conducted on university students; no significant difference was determined in constant anger, anger control, outpouring anger and introvert anger sub-dimensions according to education levels of fathers of the students doing sports. However, there was a significant difference in the constant anger sub-dimension of the students who did not do sports according to fathers' education level. In the studies conducted by Gulveren (2008), Gulec (2002), Kuruoglu (2009) and Altuntas (2012), no statistically significant difference was found between the father's education levels and constant anger, introvert anger, outpouring anger and anger control sub-scales. When the different findings of our study were examined more closely, it was concluded that the participants whose fathers were high school graduates and undergraduate degree graduates had close average scores and therefore they had an effect on their children to suppress their anger as the father's education level increased. Dilek et al. (2016) in their studies; father's education level did not affect adolescents' constant anger and all anger types; however, education level of mothers affects anger control factor only. These findings suggest that education level of mothers and fathers does not affect anger emotion in adolescents are all. The fact that the anger control level increased as the education level of mothers increases, make us thought that mothers raised their children to provide anger control as education level increased.

In the study, the introvert anger scores of the participants with sport experience of 1-2, 3-4, 5-6 years were found to be lower than those with sport experience of 9 years or more. According to this result, the introvert anger scores increased as the sport experience increased. Outpouring Anger scores of the participants with of 1-2 years and above 9 years were higher than those with 3-4 years of sports experience. Anger-Control scores of the participants with a sport experience of 9 years or more were found to be significantly higher than those with a sport experience of 1-2, 3-4 and 5-6 years. In the study of Kizmaz (2004), it was concluded that as the year of doing sports increased, social maturity and skill aspect developed and these athletes developed themselves as athletes recognizing the rights of competitors, increased self-confidence and avoiding harm others. Yildiz (2008) in his study on football players, concluded that long or short term of sports experience had not an effect on the type and control of anger. As a result of Nas's (2017) study on football players, inexperienced footballers could not suppress their anger and reflected their anger more outwardly, anger was better controlled with the increase of experience and sports year, however after many years, it was again determined that outpouring anger factor was come to prominent with the concerns of reaching to the end of the sports career. According to these results, results of our study and the results of the studies in the literature were evaluated to have similar characteristics. As a conclusion; It has been concluded that those who are interested in a sport branch for 1-2,3-4 and 5-6 years cannot control, repress and reflect their anger because they are inexperienced. In other words, the ability to use anger emotion in a positive means develops in parallel with sports career. As in our study, after a certain year, it was concluded that because of the approach to the end of the sports career, the feeling of anxiety increased and the athletes could start to reflect their anger to outside, so their outpouring anger scores increased again.

Outpouring Anger scores of participants who participated in an international competition were lower than those who did not participate in an international competition and anger-control scores were higher than those who did not participate in an international competition In a study by Stevens and Lane (2001), the methods used by athletes to regulate their emotions were examined and they preferred to be alone in order to control their anger, they analyzed the situation to relieve confusion, they used different activities to deal with depression, and they used relaxation methods. When the literature is examined, it is evaluated that athletes perceive negative feelings 
such as anger as useful and use it for functional performance improvement. Robazza, Bertollo and Bortoli (2006) in their study; attributed the high level of anger to the presence of competition. In a study conducted by Lane, Beedie, Devonport and Stanley focused on runners, it was concluded that $15 \%$ of individuals though that feelings of anxiety and anger increase sportive performance and $85 \%$ of them though that controlling of these emotions had positive effects on performance. While the appropriate level of anxiety affects sports performance positively, the thoughts that cause this anxiety affect the general adaptation of people negatively. In line with the findings of the above study, it has been evaluated that especially team athletes use anger as a performance enhancing factor in the game, especially athletes with an international competition experience are more successful in not reflecting their anger and they develop an effective anger control skill. It is another result of this research that this skill can be developed by professional coaches, being influenced by professional athletes and being motivated in order to be successful.

\section{References}

Altuntas, G. (2012). Comparison of Continuous Anger and Anger Expression Style, Self-Esteem and Anxiety Levels of Divorced Parents and Children of High School First, Second, Third Classes of Non-Divorced Parents. Master Thesis, Maltepe University Institute of Social Sciences, Istanbul.

Amedahe, F. K., \& Owusu-Banahene, N. O. (2007). Sex Differences in the Forms of Aggression Among Adolescent Students in Ghana. Research in Education, 78, 54-64. https://doi.org/10.7227/RIE.78.5

Andersen, M. B. (2006). It's All About Sport Performance and Something Else. In J. Dosil (Ed.), The Sport Psychologist's Handbook: A guide for sport-specific performance enhancement Chichester (pp. 687-698). UK: John Wiley \& Sons. https://doi.org/10.1002/9780470713174.ch30

Bahadır, Z., \& Certel, Z. (2012). Investigation of Self-Esteem and Continuous Anger and Anger Expression Style Relationship in Team Sports Athletes. Selcuk University Journal of Physical Education and Sports Science, 14(2), 157-164.

Balkaya, F., \& Sahin, N. H. (2003). Multidimensional Anger Scale. Turkish Journal of Psychiatry, 14(3), 192202.

Batıgün, A. D., \& Utku, Ç. (2006). Investigation of the Relationship Between Eating Attitude and Anger in a Group of Young People. Turkish Journal of Psychiatry, 21(57), 65-78.

Baygol, E. (1997). Investigation of Adolescent Anger Responses. Master Thesis, Uludag University, Bursa.

Beedie, C. J., \& Lane, A. M. (2012). The Role of Glucose in Self-Control Another Look at the Evidence and an Alternative Conceptualization. Personality and Social Psychology Review, 16(2), 143-153. https://doi.org/10.1177/1088868311419817

Beedie, C. J., Terry, P. C., \& Lane, A. M. (2000). The Profile Mood States and Atlethic Performance: Two Meta Analyses. Journal Apllied Sport Psychology, 12, 49-68. https://doi.org/10.1080/10413200008404213

Bostanc1, N., Coban, Ş., Tekin, Z., \& Ozen, A. (2006). How University Students Express Anger According to Gender. Crisis Journal, 14(3), 9-18.

Coopersmith, S. (1967). The Antecedents of Self-Esteem. W. H. Freeman and Company, San Francisco.

Cuhadaroglu, F. (1986). Self-Esteem in Adolescents. Published Specialization Thesis, Hacettepe University Faculty of Medicine, Ankara.

Dilek, O., Erol, O., Aynur, Ç., \& Ipek, Ö. A. (2016). Continuous Anger and Anger Expression Styles in Adolescents. Anatolian Journal of Psychiatry, 17, 65-73. https://doi.org/10.5455/apd.176085

Gross, J. J., \& Barrett, L. F. (2011). Emotion Generation and Emotion Regulation: One or Two Depends on Your Point of View. Emotion Review, 3(1), 8-16. https://doi.org/10.1177/1754073910380974

Gulec, Y. (2002). The anger experiences of adolescents, their self-perceptions and academic success (pp. 110142). Unpublished Master Thesis. Marmara University Institute of Educational Sciences. Istanbul.

Gulveren, H. (2008). Investigation of the Relationship Between Internal-External Control Focus, Continuous Anger and Anger Expression Style and Intelligence in High School Senior Students (pp. 111-140). Maltepe University Institute of Social Sciences Master Thesis, Istanbul.

Hanin, Y. L. (2010). Coping with Anxiety in Sport. In A. R. Nicholls (Ed.), Coping in sport: Theory, methods and related constructs (pp. 159-175). Nova Science Publishers.

Hassmen, P., Koivula, N., \& Uutela, A. (2000). Physical Exercise and Psychological Wellbeing: A Population 
Study in Finland. Preventive Medicine, 30(1), 17-25. https://doi.org/10.1006/pmed.1999.0597

Herguner, G. (1991). The Role and Importance of the Family in Turning the Child to Sports. University Journal of Education Faculty, 6(1), 91-95.

Jones, M. (2003). Controlling Emotions in Sport. The Sport Psychologist, 17, 471-486. https://doi.org/10.1123/tsp.17.4.471

Kanoglu, E. (2008). Anger Levels of High School Students and Investigation of Anger Expressions. Master Thesis, Haliç University Institute of Health Sciences, Istanbul.

Karatas, Z. (2008). Anger and Aggression in High School Students. CU Journal of Social Sciences Institute, $17(3), 277-294$.

Kennedy, H. G. (1992). Anger and Irritability. British Journal of Psychiarty, 161, 145-153. https://doi.org/10.1192/bjp.161.2.145

Kısac, İ. (1997). Continuous Anger and Anger Expression Levels of University Students According to Some Variables. Doctoral Thesis, Hacettepe University, Institute of Social Sciences, Ankara.

Kızmaz, M. (2004). Comparison of Personality Traits of Individual and Team Sports Athletes. Master Thesis, Marmara University, Istanbul.

Kuru, E. (2003). Personality Traits of Physical Education Department Students with Different Status. Gazi University Journal of Gazi Education Faculty, 23(1).

Kuruoglu, D. (2009). Relationship Between University Students' Continuous Anger Levels, Anger Expression Styles and Obsessive Compulsive Symptoms. Master thesis, Maltepe University Institute of Social Sciences, Istanbul.

Lane, A. M., Beedie, C. J., Devonport, T. J., \& Stanley, D. M. (2011). Instrumental Emotion Regulation İn Sport: Relationships Between Beliefs About Emotion and Emotion Regulation Strategies Used by Athletes. Scandinavian Journal of Medicine ve Science in Sports, 21(6), 445-451. https://doi.org/10.1111/j.1600-0838.2011.01364.x

Lazarus, R.S. (2000). Cognitive-Motivational-Relational Theory of Emotion. In Y. L. Hanin (Ed.), Emotions in sport (pp. 39-63).

Moll, T., Jordet, G., \& Pepping, G. J. (2010). Emotional Contagion in Soccer Penalty Shootouts: Celebration of İndividual Success is Associated with Ultimate Team Success. Journal of Sports Sciences, 28(9), 983-992. https://doi.org/10.1080/02640414.2010.484068

Nas, K. (2017). Determination of Aggression Levels and Anger Styles of Football Players (pp. 109-133). Gazi University Institute of Health Sciences. Doctoral Thesis. March 2017.

Nesse, R. M., \& Ellsworth, P. C. (2009). Evolution, Emotions, and Emotional Disorders. American Psychologist, 64(2), 129. https://doi.org/10.1037/a0013503

Olmus, G. Ö. (2001). Investigation of Continuous Anger and Anger Expression Styles of Adolescents According to Family Psychological Patterns. Master Thesis, Marmara University, Istanbul.

Opoz, T. (2017). The Relationship Between Emotional Regulation Skills, Social Anxiety and Anger Levels of Adolescents Engaging in Sports or Art (pp. 7-22, 39-44). Ankara University Institute of Social Sciences. Master Thesis.

Ozer, A. K. (1994). Continuous Anger and Anger Expression Style Preliminary Study. Turkish Journal of Psychology, 9(31), 26-35.

Ozmen, D., Ozmen, E., Cetinkaya, A., \& Akil, İ. Ö. (2016). Continuous Anger and Anger Expression Styles in Adolescents. Anatolian Journal of Psychiatry, 17, 65-73. https://doi.org/10.5455/apd.176085

Ozturk, A. S. (2007). The Effect of Sport on Socialization of Orthopedically Disabled. Master thesis, Gazi University Institute of Health Sciences Physical Education Sports Department, Ankara.

Perkins, D., Wilson, G. V., \& Kerr, J. H. (2001). The Effects of Elevated Arousal and Mood on Maximal Strength Performance in Athletes. Journal of Applied Sport Psychology, 13(3), 239-259. https://doi.org/10.1080/104132001753144392

Robazza, C., Bertollo, M., \& Bertoli, L. (2006). Frequency and direction of competetive anger in contact sports. Journal Sports and Medicine Physical Fitness, 46(3), 501-508. 
Sezan, T. (2016). Anger Expression Styles of University Students Who Do Sports and Do Not (pp. 32-65). Selcuk University Institute of Health Sciences. Master Thesis.

Starner, T. M., \& Peters, R. M. (2004). Anger expression and blood pressure in adolescents. The Journal of School Nursing, 20(6), 335-342. https://doi.org/10.1177/10598405040200060801

Stevens, M. J., \& Lane, A. M. (2001). Mood-Regulating Strategies Used by Athletes. Athletic Insight, 3(3), 112.

Sunay, H., \& Saracaloglu, S. (2003). The Aspects of the Turkish Athlete in Sports with the Expectations of Sports. Spormetre Physical Education and Sports Science Journal, 1(1), 43-48.

Tambag, H., \& Öz, F. (2005). Ways of Adolescents Expressing Anger in Their Dormitories with Their Families and Orphanages. Crisis Journal, 13(1), 11-21.

Tamir, M. (2009). What do People Want to Feel and Why? Pleasure and Utility in Emotion Regulation. Current Directions in Psychological Science, 18, 101-105. https://doi.org/10.1111/j.1467-8721.2009.01617.x

Tanriverdi, H. (2012). Sports Ethics and Violence. The Journal of Academic Social Science Studies, 5, 10711093. https://doi.org/10.9761/jasss_361

Tuzgol, M. (1998). Investigation of Aggression Levels of Parent Attitudes of Different High School Students in Terms of Various Variables. Master Thesis. Hacettepe University Institute of Social Sciences. Ankara.

Yildiz, M. (2008). Investigation of Personality Types and Continuous Anger-Anger Expression Styles of Football Players in Different Leagues. Doctoral Thesis. Gazi University. Health Sciences Institute, Ankara.

\section{Copyrights}

Copyright for this article is retained by the author, with first publication rights granted to the journal.

This is an open-access article distributed under the terms and conditions of the Creative Commons Attribution license (http://creativecommons.org/licenses/by/4.0/). 